\title{
O fato religioso ao rés do chão: teoria e método para a pesquisa do campo religioso do antigo Israel
}

\author{
The religious fact in the shallows of the ground: theory and method for the \\ research of the religious field of ancient Israel
}

João Batista Ribeiro Santos*

\begin{abstract}
Resumo
O objetivo deste artigo é apresentar uma pesquisa sobre a teoria e o método historiográfico aplicado ao campo religioso do antigo Israel, com postulados que abordam os contextos do antigo Oriente-Próximo, na qual as fontes literárias e artefactuais são os agentes sociais na reconstrução do acontecimento. A definição de "História" e sua conceituação precedem o debate acerca das fontes, inclusive a sua raridade - circunstancialidade que leva-nos ao estabelecimento de valor aos indícios -, e da visão de mundo dos protagonistas revelada por meio das memórias culturais. Aqui, nas memórias, estão a natureza da sociedade e seu tempo. Por isso, a partir da fundamentação teórica inicial apresentaremos a aporia que fornecerá as questões para a busca por evidências e fatos (conteúdos) históricos, assim como as vinculações do campo religioso com validade metodológica para as linguagens culturais, com as quais consideraremos as realidades mentais - sendo estas quase sempre documentadas como resultados objetivos de fatos criados para a rememoração coletiva. Nossa hipótese é que o "fato puro" pode ser reconstruído por meio de fontes literárias, mas sua veridicidade deverá ser testada na presença de artefatos, por isso a nossa pesquisa é desenvolvida considerando os contextos, as tradições e normativas, sendo-lhe adequado o método comparativo.
\end{abstract}

Palavras-chave: Teoria e método; historiografia; campo religioso; memória cultural; antigo Israel.

\begin{abstract}
The objective of this article is to present a research on the historiographic theory and method applied to the religious field of ancient Israel, with postulates that approach the contexts of the ancient Near East, in which literary and artifactual sources are the social agents in the reconstruction of the event. The definition of "History" and its conceptualization precede the debate about sources, including their rarity - circumstantiality that leads us to value the evidence -, and the world view of the protagonists revealed through cultural memories. Here in the memories are the nature of society and its time. Therefore, from the initial theoretical foundation we present the logical difficulty that will provide the questions for the search for evidence and historical facts (contents), as well as the linkages of the religious field with methodological validity for the cultural languages, with which we will consider the mental realities these being almost always documented as objective results of facts created for the collective remembrance. Our hypothesis is that "pure fact" can be reconstructed through literary sources, but its veridicity must be tested in the presence of artifacts, so our research is developed considering contexts, traditions and regulations, the comparative method being appropriate.
\end{abstract}

Keywords: Theory and method; historiography; religious field; cultural memory; ancient Israel.

Artigo submetido em 16 de maio de 2019 e aprovado em 21 de agosto de 2019.

*Doutor em Ciências da Religião pela UMESP. Professor da UMESP. País de origem: Brasil. E-mail: joao.ribeiro@metodista.br 


\section{Fundamentação introdutória}

Definimos a História como campo de aplicação do conhecimento histórico especificamente científico e a pesquisa como processo de constituição narrativa de sentido, que tem como um dos seus domínios a apresentação historiográfica. Por outro lado, a arqueologia presta contas do passado com base em dados físicos. ${ }^{1}$

Seja de que modo que a consciência histórica penetre no passado - por mais longe que sua dimensão temporal se estenda nas profundezas do passado ou que possa ainda parecer que percamos de vista, no itinerário dos arquivos da memória, os problemas do presente -, o impulso para esse retorno, para esse resgate do passado, para essa dimensão de profundidade e para o itinerário dos arquivos é sempre dado pelas experiências do tempo presente. Não há outra forma de pensar a consciência histórica, pois é ela o local em que o passado é levado a falar e o passado só vem a falar quando questionado. (RÜSEN, 2001, p. 63).

É aqui que a narrativa histórica firma-se como consciência histórica, posto requerer uma atividade intelectual que evidencia o passado, como trabalho interpretativo, consciente de que o passado se constitui dos fatos humanos realizados. Objetivamente, as experiências do tempo determinantes do agir, mas com espaço para a memória. A razão dessa objetividade tem a intenção de obter a verdade especificamente científica do evento (ou dos eventos) narrado que pretendemos investigar, e quando possível apresentar a fundamentação da sua credibilidade e a pertinência narrativa quanto ao modo como narra o evento.

Desta forma, para a pertinência, serão imprescindíveis os vestígios desse mesmo evento ainda preservados, como testemunhos fundamentadores da realidade passada, ${ }^{2}$ sem abstrair-se do fato de que "a narrativa de histórias é vinculada, pois, ao recurso às fontes: ou seja, narrar argumentativamente o que depõe a favor ou contra o que no passado tenha ocorrido ou não, da forma como é narrado" (RÜSEN, 2001, p. 102). Em relação às fontes, elas precisam estar metodologicamente organizadas em função das hipóteses; nesse caso, a objetividade será assegurada sobre a subjetividade para que a pesquisa histórica

\footnotetext{
${ }^{1}$ Como dado esclarecedor, "prestação de conta do passado é um ato de equilíbrio entre distintas formas de inferência a partir de evidência, e às vezes decidindo entre elas" (JEFFARES, 2011, p. 330).

${ }^{2}$ A metodização da ciência da história foi desenvolvida por Jörn Rüsen (2001, p. 95-147). Quanto aos referenciais teóricos, eles estarão expostos neste "Fundamento" e seus autores, relacionados na bibliografia.
} 
obtenha maior validade, baseada no pressuposto de que "não há historiografia que não pretenda ser verdadeira, o que a remete forçosamente à pesquisa" (RÜSEN, 2010, p. 22).

A isso emerge outro lance epistemológico, considerando que a tarefa do historiador consiste primordialmente em buscar a evidência da hipótese e transmiti-la: a opinião recorrente acerca da necessidade de adotar-se um ponto de vista ou a parcialidade, o que limita tanto os testemunhos quanto o historiador ainda que a imparcialidade na narração admita que o narrador tenha um ponto de vista. Esse procedimento nem sempre deve ser tomado como um julgamento crítico sobre o que interessa à história. Segundo Reinhart Koselleck (2011a, p. 161-163), admite-se a relativização do conhecimento histórico. Diante deste impasse, entendemos que não apenas subjetividade e objetividade se excluem, mas também partidarismo e objetividade, como potencialidades racionais, excluem-se mutuamente, apesar de poderem encontrar-se ao longo da pesquisa.

A teorização do sentido do pensamento histórico deverá ser submetida às regras metódicas para que fique clara a sua relação com os fatos humanos, perseguindo sempre a possibilidade da objetividade - ainda que "histórias por princípio tomam e têm de tomar 'partido', se quiserem ser, de fato, histórias" (RÜSEN, 2001, p. 127) -, caso a intenção do historiador seja expor no fluxo do tempo, mediante a memória histórica, as diversas posições existentes na vida social. A produção objetiva de conhecimento histórico baseado na pesquisa dos artefatos possibilita a verificação e a diferenciação, possibilita também a verificação pelo testemunho empírico das asserções.

Interpretação é a operação metódica que articula, de modo intersubjetivamente controlável, as informações garantidas pela crítica das fontes sobre o passado humano. Ela organiza as informações das fontes em história. Ela as insere no contexto narrativo em que os fatos do passado aparecem e podem ser compreendidos como história. Como ela transforma fatos em história(s), deve ser considerada como a operação de pesquisa própria, especificamente histórica. (RÜSEN, 2007, p. 127). 
Determinado por critérios de sentido - vinculados aos resultados do conhecimento histórico, aceitando a conceituação de que a própria pesquisa já produz sentido em seu procedimento de interpretação -, a interpretação histórica avalia os eventos, vinculada ao seu significado para o contexto histórico pesquisado. Assim sendo, a pesquisa se ocupará da realidade dos eventos, na qual as fontes deverão se manifestar perceptivelmente, comparativamente, demonstrando o passado, partindo de uma hipótese acerca da origem. ${ }^{3}$ Assumimos como intencional o fato de que "a escrita da história responde à necessidade de explicar as mudanças sociais e de estabelecer bases para um novo significado" (SETERS, 2008, p. 22), investigando a veridicidade dos "fluxos de tradição" disponíveis porque "a interpretação histórica obedece, pois, ao princípio metódico da plausibilidade explicativa" (RUSEN, 2007, p. 130).

A historiografia e a investigação dos documentos, então, terão o intuito de expor, com efeito, os objetivos da pesquisa na sua íntegra e colocá-los como que diante dos olhos; assim, a demonstração crítica das provas documentais impõe-se à guisa de evidência na narrativa. Lembrou-nos Carlo Ginzburg (2007, p. 284; 293) que, ao contrário dos antropólogos, os historiadores não são capazes de produzir as suas fontes; dentre outras implicações, precisamos ter consciência, portanto, dos aspectos e das relações textuais etnográficas. Não existem textos neutros, justificou Ginzburg (2007, p. 288), o etnógrafo faz seu o que ouviu, que é remodelado, por sua vez, por quem cita.

Expliquemos: o mesmo Ginzburg (2007, p. 312) ressalta que "o historiador é, por definição, um pesquisador a quem os experimentos, no sentido próprio do termo, são vedados". E como não podemos - também! - constatar os fatos ou

\footnotetext{
3 “'Origem' é a noção de existir uma fonte do objeto que estiver sendo considerado, uma volta à qual é muitas vezes vista como o objeto da busca racional. A procura das origens é uma tentativa de enxergar, por trás ou além dos fenômenos, seu fundamento último. Para as filosofias modernas do eu - existencialismo, psicanálise, fenomenologia etc. -, a tentativa de descobrir a origem do eu constituiria o caminho da autenticidade. O pós-modernismo nega tal possibilidade. Contesta ser factível voltar a captar ou mesmo representar a origem, fonte, ou qualquer realidade mais profunda por trás dos fenômenos; lança dúvidas até mesmo sobre sua existência, ou chega a negá-la taxativamente. Num sentido, tal corrente é intencionalmente superficial; não por negar que se deva proceder a análises rigorosas, mas por considerar a superfície das coisas - os fenômenos - como algo que não requer uma referência a qualquer coisa mais profunda ou fundamental. Esta é uma das diferenças centrais entre estruturalismo e pós-estruturalismo. Assim, por exemplo, no exame de um texto, as intenções do autor não seriam especialmente relevantes para sua compreensão, estando em igualdade de condições com quaisquer outras considerações: elas não são a 'origem' do texto, portanto, não têm qualquer 'privilégio' ou 'autoridade' maiores do que os que teriam outros fatores." (CARDOSO, 2005a, p. 87).
} 
reproduzir os eventos, pois o passado é um dado que nada mais modificará, baseamo-nos para o critério de cientificidade na noção de fonte documental porque trabalhamos com fontes, respectivamente, as provas. Felizmente, a longo termo, para aceder a um enunciado de Marc Bloch (2009, p. 72-73), sempre restam vestígios a que devemos nos ocupar com a devida atenção, não diferenciando o grau de interesse das narrações ou textos, na ordem documentária, e do evento, na ordem dos fatos:

Ossos, vasos, e as fundações são desenterrados. Limites do campo, rotas de caminho, e as características arquitetônicas são examinados. Os vivos são questionados oralmente. Dados sobre atividade econômica são acumulados e exibidos na forma de listas ou tabelas. No centro dos esforços de reconstrução da maioria dos historiadores estão obras escritas: memórias, crônicas, cartas, encomendas, atas, registros legais e muito mais (DAY; RADICK, 2011, p. 87).

As matérias que fornecem ou deixam de fornecer suporte empírico às hipóteses são a evidência. Naturalmente, a primeira necessidade de uma pesquisa histórica é não restringir-se apenas em registrar as palavras de uma testemunha epigráfica ou artefactual, por exemplo, mas questioná-la, fazê-la falar. Mais importante: "No princípio, diriam de bom grado, eram os documentos. O historiador os reúne, lê, quer dizer, critica, empenha-se em avaliar sua autenticidade e veracidade. Depois do que, e somente depois, os põe para funcionar...” (BLOCH, 2009, p. 78-79). Com o mesmo espírito, deve-se informar tudo acerca dos documentos, buscando a elucidação do tema (ou temas) sumarizado. Mas essa asseveração é válida para o caso de contarmos efetivamente com as fontes.

A raridade da documentação levou os historiadores gregos e latinos a obterem informações circunstanciais e a análises a partir do ponto de vista (FINLEY, 2001a, p. 53; ALTER, 2007, p. 64). Algo atualmente inaceitável, mesmo para a historiografia de um povo que registrou sua origem envolta a tradições tardias, movimentos vitais retroprojetados e memórias anacrônicas, fundados ora 
em prosas de ficção, ora em realidade coetânea (do tempo da narração ${ }^{4}$ ). Nesse sentido, a literatura hebraica antiga permite ao acesso das tradições a sua fenomenalidade, como a maneira de o povo reconhecer-se, o que não nos impede de afirmar que não dispomos de um instrumento plausível da transmissão oral de um saber detalhado sobre os eventos fundantes do antigo Israel (Yiśrāèel).

Porém, como meio de informação, o que importa é estabelecer o possível debate epistemológico em torno da relação entre as narrações e os fatos que descrevem (THEML, 2002; CARDOSO, 2005a, p. 73-94). Evidentemente, torna-se imprescindível a memória cultural, disposta nos artefatos, para se encontrar os referentes da investigação científica e tentar captar e posteriormente decifrar algum sistema de significação que poderá avançar além da episteme.

Diante disso, a questão, óbvia, mas relevante, a ser colocada à luz de uma descoberta arqueológica é esta: a tradição feita historiografia é confirmada e esclarece o debate? Esta questão assim colocada serve à análise da documentação textual. As evidências podem ser resultado de um conjunto de elementos estruturados, denominado memória individual ou, de forma mais abrangente, experiência local, que pode ser tomado como recordação ou, particularmente no caso do antigo Israel, memória coletiva. Nesse caso, ainda quando seja uma memória histórica, 5 tende a funcionar como constituição nacional, vigorando como instância organizadora da consciência social e estabelecendo critérios religiosos, políticos, econômicos, forenses. Esses critérios são memórias, eventualmente inventadas, apropriadas, ainda que sejam submetidas ao processo de reinvenção cultural, e, sobretudo, herdadas como tradição.

\footnotetext{
${ }^{4}$ Citando Émile Benveniste, Jacques Le Goff (2012, p. 207-208) estabelece a importante distinção do tempo: “a) tempo físico, 'contínuo, uniforme, infinito, linear, divisível à vontade'; b) tempo cronológico ou 'tempo de acontecimentos' que, socializado, é o tempo do calendário; c) tempo linguístico, que 'tem o próprio centro no presente da instância da palavra', o tempo do locutor". Interessa-nos o tempo cronológico, que chamaremos de "tempo da narração", e o tempo linguístico, que chamaremos de "tempo do narrador". Assim admitimos as cronologias históricas e não históricas de sentido do passado.

5 "Memória emprestada pela coletividade ao indivíduo sobre coisas e processos do passado que não vivenciou pessoalmente" (CARDOSO, 2005a, p. 19).
} 


\section{Aporia}

Os monumentos e anais raramente expõem a visão de mundo dos protagonistas de acontecimentos, ela é quase sempre presumida, sem a qual nada teríamos acerca da mentalidade do ser humano em uma determinada época da Antiguidade. Por outras palavras, nos defrontamos com o pensamento que se desgarra dos objetos (inscrições e ícones imagéticos ou fontes artefactuais), mas que nem sempre faz parte do conteúdo da arqueologia histórica e da reconstrução dos modos de ser. Portanto, buscamos a possível perspectiva na afixação de História, ${ }^{6}$ ou das culturas materiais7 e traditivas, no antigo Israel - remontar e explanar o acontecimento. ${ }^{8}$ Está ausente dessa perspectiva a sacralização por si das linguagens, mas não como possibilidade post eventum num grupo social ou a posteriori da própria artesania da imaginação iconográfica. No plano de fundo está o saber como capacidade inspirada e o motivo do escriba, ou seja, sincronizar por meio da narração o leitor e o fato histórico, visando preencher os espaços narrativos com as minúcias identitárias coletivas.

O trabalho transdisciplinar é o que melhor serve como guia para a investigação dos processos civilizatórios e de etnicidade do povo israelita. A explanação baseada nas respostas das fontes poderá elucidar o acontecimento mantido encoberto por matérias religiosas e em meio a ditos e versões contrastantes. Destarte, privilegiar o factual é uma tarefa retomada recentemente pelos historiadores. Referimo-nos à desvalorização dos documentos literários em favor dos monumentos (relevos, estátuas e estatuetas, cilindros, obeliscos e murais; moedas, medalhas, parafernália cúltica e vasilhas do ambiente doméstico) a partir

\footnotetext{
${ }^{6}$ Para uma significância, ao mesmo tempo definição que norteará a nossa pesquisa: "História, com efeito, é a ciência da diferença. Não basta calibrar a oposição de um 'agora' contra um 'antigamente'; é preciso identificar a substância passada do passado (aquilo que em inglês se diz 'pastness'), sem prejuízo dos interesses e direitos do presente" (MENESES, 1992, p. 12). Para nós, isto é programático.

7 "A memória, nesse sentido particular, é caracterizada inicialmente como afecção (pathos), o que a distingue precisamente da recordação" (RICCEUR, 2014, p. 35). E aqui ficará diferenciada de souvenir, para falarmos da memória em si mesma, pois "como construção social, é formação de imagem necessária para os processos de constituição e reforço da identidade individual, coletiva e nacional. Não se confunde com a História, que é forma intelectual de conhecimento, operação cognitiva. A memória, ao invés, é operação ideológica, processo psico-social de representação de si próprio, que reorganiza simbolicamente o universo das pessoas, das coisas, imagens e relações, pelas legitimações que produz" (MENESES, 1992, p. 22).

${ }^{8}$ À guisa de elucidação: "O fato não é o acontecimento, ele próprio devolvido à vida de uma consciência testemunha, mas o conteúdo de um enunciado que visa a representa-lo." (RICCEUR, 2014, p. 190).
} 
do final do século XVIII da nossa era, desconsiderada, portanto, uma das conviç̧ões do fazer da história pelos gregos.

Jacques Revel (2009) traz o tema ao debate e empenha-se por provar o apoio da segunda geração dos Annales em "desembaraçar-se do acontecimento" pela impossibilidade de qualquer conhecimento científico do "fato puro", envolvendo o individual, o político e o cronológico. À parte o sociólogo durkheimiano François Simiand, foi Fernand Braudel com suas ênfases nas mentalidades que, na avaliação de Revel (2009, p. 76), "mais intensamente tematizou a recusa do acontecimento. Fez isso reivindicando a preeminência da longa duração, ou seja, de um tempo histórico subtraído aos acidentes”. Como saldo, defendeu-se a metodologia quantitativa e prescritiva na qual os movimentos vitais $^{9}$ de curto prazo, suas estruturas e realidade social são ignorados.

O acontecimento é uma sucessão de fatos, na perspectiva diacrônica. A narrativa é sincrônica, evidenciando os fatos e a mudança na ordem do tempo. Destaque-se: recolocar a ênfase no acontecimento é pensar o tempo social para além das durações mais pesadas e "considerar a experiência temporal dos atores, é reabrir à análise uma dimensão que os historiadores geralmente abandonam porque eles trabalham sobre processos que são vencidos, a incerteza com a qual todo ator social se vê confrontado" (REVEL, 2009, p. 94-95). A experiência temporal "vivida ao ritmo de sua vida, breve como a nossa", e por isso invalidada por Braudel. Portanto, caracteriza-se pela pesquisa dos contextos mirando o descobrimento das formas e dos motivos da ação que desencadeiam o fato histórico.

Com efeito, "a escrita da história responde à necessidade de explicar as mudanças sociais e de estabelecer bases para um novo significado, uma nova autoridade e legitimação daquelas formas tradicionais que deixaram de ser funcionais em situação de mudança social” (SETERS, 2008, p. 22). Isso pode ser

\footnotetext{
${ }^{9}$ Sempre que mencionarmos "movimentos vitais" teremos em mente o liame dos fatos, tanto como significação quanto como relação, na forma enunciada por Marc Bloch (2009, p. 134).
} 
aplicado às práticas cúlticas e suas representações, abandonadas como experiências sociais na medida em que as estruturas e as funções do Estado substituem as reciprocidades familiais. A impossibilidade de impedir o esquecimento de fatos de importância individual e a translação de cultura autóctone devem-se à força da legitimação jurídica, quando, por exemplo, transforma a narração biográfica (ficcional ou não) dos feitos de um rei em parte central da história do povo e, em seguida, em tradição ${ }^{10}$ e regra. Dentre as inúmeras tradições e normativas israelitas, esta última afixação coletiva não prevaleceu completamente em face à desqualificação pública a que os reis israelitas sofreram por parte dos últimos historiógrafos e editores da assim chamada História Deuteronomística. ${ }^{11}$

Por outro lado, a supervalorização dos procedimentos escribais sugere esquecimento dos usos de fórmulas extraídas de anais e crônicas fenícias e mesopotâmias, além de listas locais independentes, na estruturação básica das composições documentárias. Acrescente-se à falta de verificação arquivística o fato de acontecimentos políticos fundantes serem frequentemente atribuídos pelos redatores deuteronomísticos a consequências religiosas, como a edição judaíta do golpe de Estado perpetrado pelo militar israelita Jehu..$^{12}$ Justifica-se, portanto, a necessidade de uma metodologia comparativamente contextual da pesquisa.

\section{Evidenciação historiográfica}

A evidência historiográfica é variada e multiforme, assim como a explanação historiográfica ou exegética pode ser teoricamente realizada por muitos métodos explanatórios. Mark Day e Gregory Radick (2011, p. 88) esclarecem que "uma compreensão epistemológica externa da evidência não é formulada em termos de crenças e suas relações, mas em termos do mundo dos efeitos e causas sobre as

\footnotetext{
${ }^{10}$ A tradição fortalece a crença, atribui significâncias e noção de identidade, legitima ou controla os modos de ser, comunica conhecimento e poder. Sobre isto, sugerimos SETERS, 2008, p. 21.

${ }^{11}$ Sobre a assim chamada Historiografia Deuteronomística, Christoph Uehlinger (2015, p. 6) chama de "uma importante vertente historiográfica na Bíblia hebraica (que é demasiado restritamente e imprecisamente designada como 'deuteronomística')". Na falta de melhor designação expressa, inclusive por Uehlinger, manteremos a identificação consagrada.

${ }^{12}$ Cf. 2 Reis 9-10. O acontecimento tem sido caracterizado como "golpe de Estado" ("Jehu's coup", "coup d'état", "military coup") por muitos pesquisadores e pesquisadoras, dentre os quais mencionaremos apenas o mais recente, Matthews (2019). Isso considerado, a tomada do poder não ocorreu por meio de sucessão, por meio de ações militares a bēt/bït historicamente estabelecida foi exterminada.
} 
quais essas crenças são formadas”. Teoricamente elucidativo, Marcelo Rede (2012, p. 147) entende que "conviria insistir sobre o fato de não haver uma relação de causa e efeito unívoca que situe as relações sociais na origem de um processo concebido abstratamente". Salientemos que sobretudo no antigo Oriente-Próximo as proposições das causas e dos efeitos são historicamente materializadas nos artefatos. No entanto, as evidências são mais ou menos prováveis por hipóteses mais ou menos prováveis, excluindo a dedução como guia para inferência.

No centro da abordagem teórica a dedução não consta para evitar alguma explanação dicotômica das fontes (aceitar ou rejeitar). As camadas literárias bíblicas e os demais documentos monumentais - relevos pictográficos - poderão demonstrar que as encenações e inscrições dos acontecimentos são ocasionais, nos quais a indeterminação dos fatos históricos possibilita ao pesquisador diferentes tipos de novas interpretações. De cada fato, resta a indefinição, pelas distintas representações e linguagens.

A explicação historiográfica de eventos particulares às vezes foi categorizada como explicação narrativa. Tais explicações são ditas para definir eventos em um contexto e colocá-los dentro de uma série de eventos que podem ser vistos como tendo um fio de conexão. É o fio de conexão que fornece a iluminação explicativa: é por causa da relevância das conexões que se vê o evento explicado como o resultado plausível (ou mesmo inevitável) do que foi antes. $\mathrm{O}$ evento teve sentido e, portanto, não é surpreendente, quando essa conta narrativa é fornecida (MACDONALD; MACDONALD, 2011, p. 136).

O acontecimento central é uma sucessão real de eventos, já o afirmamos. A natureza cultural das ações nas sociedades revela a experiência do âmbito das políticas comunitárias específica,13 objetivada por meio das fontes. Essa cultura material é interpretada como produto social; ${ }^{14}$ não obstante, é fato social gerado no centro das construções de identidades. Ora, esses processos, mesmo quando estruturais ou de longa duração, são geradores das funções da sociedade, como afirmou Émile Durkheim (2014, p. 461), “a civilização é obra da sociedade”. Há que se notar que conceitualmente o termo civilização emerge do binômio

\footnotetext{
${ }^{13}$ Como produtos sociais, a literatura e os monumentos prestam serviço institucional; sobre a legitimação do poder, ver Villard (2014).

${ }^{14}$ Algumas pesquisas têm seguido uma abordagem em perspectiva metodológica sobre a inscrição literária e relevos pictóricos como cultura material (MENESES, 1992; REDE, 2012; SANTOS, 2018a; 2018b; 2018c).
} 
Ocidente/Oriente, denominações ambíguas, segundo Yolanda Espiña (2014, p. 149-150; 152-153), dentre outras coisas porque tem por companhia "conceitos como barbárie, ou selvagismo, e da sua correspondente superação”.

Teoricamente a abordagem comparativa de fontes documentárias contribui com as buscas por reconstrução dos modos de ser israelitas. ${ }^{15} \mathrm{~A}$ comparação não reduzirá a pesquisa a mostras de diferenças entre os objetos analisados, procedimento redutor e impeditivo da compreensão da sociedade. ${ }^{16}$ No caso das narrações da Bíblia hebraica, elas deverão ser submetidas ao critério da equivalência literária ou aposição para o estabelecimento de debate na reconstrução dos fatos, relativamente pertinente aos objetivos e hipóteses. É válida a premissa de que o principal dever do historiador é a crítica do documento, ${ }^{17}$ não a sua afirmação pura e simplesmente, e estabelecer os fatos. ${ }^{18}$ Mas o documento está morto; quando analisado, estará em processo:

Em história, tudo começa com o gesto de separar, de reunir, de transformar em "documentos" certos objetos distribuídos de outra maneira. Essa nova distribuição cultural é o primeiro trabalho. Na realidade, ela consiste em produzir tais documentos, pelo simples fato de recopiar, transcrever ou fotografar esses objetos mudando ao mesmo tempo o seu lugar e o seu estatuto. Esse gesto consiste em "isolar" um corpo, como se faz em física, e em "desfigurar" as coisas para constituí-las como peças que preencham lacunas de um conjunto proposto a priori (CERTEAU, 2011, p. 69).

O problema que persiste desde os historiadores gregos e latinos consiste em que "a raridade das fontes literárias primárias é uma maldição para a história antiga por completo" (FINLEY, 2001a, p. 46), não obstante as evidências arqueológicas dominarem no tempo presente os debates acadêmicos. O questionamento do passado é a que existe na consciência social histórica, perspectivamente a metodologia permite ultrapassarmos as mnēmēs coletivas

\footnotetext{
${ }^{15}$ Ao "antigo Israel" referimo-nos ao conjunto das populações do norte e do sul, seja no "período tribal", seja no "período monárquico" sem, necessariamente subentender um "reino unido".

16 "Sociedade" refere-se a um grupo de pessoas que vivem juntas de alguma forma organizada, embora algumas delas possam ser oriundas de culturas diferentes; com relação às instituições sociais, elas são específicas ou agrupamentos que organizam a sociedade, não apenas no nível macro, mas também no nível das práticas e decisões cotidianas, sendo que o parentesco é um a specto da estrutura social (LEMOS, 2016, p. 381).

${ }^{17}$ Eis o ponto-chave para a operação historiográfica, segundo Jacques Le Goff (2012, p. 519). François Hartog (2013, p. 253) afirma que Michel de Certeau Ihe "ensinou a questionar a evidência ou as evidências da história"; ver Certeau (2011).

18 "Estabelecer os fatos" é o principal dever do historiador, segundo Moses I. Finley (2001c, p. 99).
} 
mesmo considerando-as indispensáveis. Uma premissa de Ferdinand de Saussure que mencionamos (LE GOFF, 2012, p. 206; SANTOS, 2018c) afirma que "o hebreu nem sequer conhece o que existe entre passado, presente e futuro", considerando que o pensamento do ser humano da Antiguidade é atemporal e apreende o mundo em sua totalidade, pois o real é sempre desdobrado. ${ }^{19}$

Essa realidade mental parece ganhar forma com os escritores israelitas e deve ser lembrada nas citações e avaliações de textos bíblicos, mas parece não determinar a escrituração na Idade do Ferro II, no qual se tem proposto os começos da escrituração israelita e período de maior orientação lógica. De certo modo, o passado é na verdade o mecanismo textual que precede a inscrição ou relevo comemorativo, em retrospecção, ${ }^{20}$ mas interpretativo dos acontecimentos.

Fundamentalmente, coexistem cronologias mentais e historicamente mensuráveis, numa característica agregação de passado e presente, observada por François Châtelet (1996, p. 12) como pertencente à esfera do mesmo e da alteridade social. Podemos assinalar que o caráter histórico apresenta-se nos contextos na medida em que é avaliada a sua proximidade com o lugar vivencial. ${ }^{21}$ Aliás, esta ênfase geográfica é vinculada ao objeto com o intuito de conferir-lhe sentido para a distinção científica da análise. A saber, mesmo que os mapas mentais sejam considerados subjetivos e elaborados a partir da percepção do espaço, com imagens elaboradas apenas pela concepção desse espaçamento mental no qual a distância mapográfica não sofre variação (LENCIONI, 2009, p. 152), as referências de local e lugar apontam-nos para algum fenômeno existencial com representações e imaginário, apesar de desterritorializações regulares.

Como parte da representação das relações sociais são mantidas por suas linguagens, "o lugar transcende sua realidade objetiva e é interpretado como um conjunto de significados. Nesse sentido, os monumentos, as obras de arte, assim

\footnotetext{
${ }^{19}$ Ao final, há aqui um primado metodológico de Claude Levi-Strauss (2013) adotado por inúmeros historiadores e antropólogos (LE GOFF, 2012; VIVEIROS DE CASTRO, 2013; 2015; SANTOS, 2018c).

${ }^{20}$ Uma chave interpretativa da apresentação "retrospectiva" e em "retroprojeção" é entender a "antiguidade" (antiquitas) como sinônimo de "autoridade" (auctoritas), "arqueologia" (archaiologĩa) e de "valor" (gravitas).

${ }^{21} \mathrm{O}$ espaço vivido, que não deve ser confundido com a região.
} 
como cidades são lugares porque são um conjunto de significados” (LENCIONI, 2009, p. 154). E são representações. Todavia, as representações mantêm relações cumulativas, ideológicas e estéticas, o que conduz à seguinte proposição: "qualquer documento é, ao mesmo tempo, verdadeiro - incluindo talvez sobretudo os falsos e falso, porque um monumento é em primeiro lugar uma roupagem, uma aparência enganadora, uma montagem" (LE GOFF, 2012, p. 522). Mas isso tem validade além do limite da ideologia para outras linguagens, como há cerca de duas décadas Manuela Carneiro da Cunha (2017, p. 353), num estudo acerca da reflexividade exemplificado inicialmente pelo paradoxo cretense, concluiu que "toda linguagem que possa falar sobre si mesma é dotada da capacidade de fazer certas afirmações que são simultaneamente falsas e verdadeiras". O monumento fala por si, mas é uma interpretação desde sua elaboração.

Em adição, o mapa e o artefato são representações dos moradores. A nosso ver, é neste sentido que Certeau (2011, p. 48) procura deixar-nos precavidos de que “os 'fatos históricos' já são constituídos pela introdução de um sentido na 'objetividade'. Eles enunciam, na linguagem da análise, 'escolhas' que lhes são anteriores, que não resultam, pois, da observação - e que não são nem mesmo 'verificáveis', mas apenas 'falsificáveis' graças a um exame crítico”. Nota-se que sem a intervenção do historiador inexistem fontes artefactuais e documentos literários.

Assim, cabe sublinhar a objetividade conceitual da mnēmē coletiva: como propriedade da história ela é reveladora da vida social (mas há o ponto de vista de quem vê!) e fornece as informações necessárias sobre os diversos eventos (depende das perguntas que lhe são dirigidas!) irreconstruíveis em função dos escassos fragmentos de estruturas, da impossibilidade de completa apreensão do pensamento individual e da organização mental à época e, não por último, da lonjura histórica. Talvez seja possível contornar a lonjura minimizando a importância dos "fatos puros" para o conhecimento. 
Associada aos tempos pessoais e das coisas - quase nunca o tempo calendárico -, espaços e vivências mentais e materiais, a mnēmē é impressão cuja função ultrapassa os temas do tempo presente e na Antiguidade dirige-se a promover a coesão de grandezas sociais. ${ }^{22} \mathrm{O}$ conceito, a função e o significado, portanto, dependem do contexto, do símbolo e da tradição. Mantêm-se atuais as sínteses lieux de mémoire (Pierre Nora), travail de mémoire (Paul Ricœur) e cadres de la mémoire (Maurice Halbwachs). ${ }^{23}$ Segundo Marie-Claire Lavabre (2011, p. 362), ultimamente a noção de mnēme "tem sido associada à questão das identidades individuais e compartilhadas", o que parece-nos fazer maior sentido no período que aqui nos interessa, posto que mesmo as atividades escribal e artesanal como um painel social ou conscientemente "autobiográfico" mantém implícito o seu gênero e explícita a sua referência. Ao sumarizar as rememorações e suas funções sociais, os historiadores e teólogos correm sempre o risco da ambiguidade!

A "memória coletiva" não é necessariamente expressa em usos mais institucionais ou políticos do passado. No entanto, a questão do impacto das condições sociais na produção de representações compartilhadas do passado, ou narrativas historiográficas públicas ou autorizadas, que muitas vezes dão sentido às memórias individuais, permanece pertinente. Além disso, pode-se argumentar que é precisamente a questão de experiências lembradas - e sua transmissão - que, ao final do dia, é posta quando a questão da memória é levantada, seja para exigir justiça ou para expressar preocupação com a reconciliação (LAVABRE, 2011, p. 368).

E a história é rememorada sempre ao final do dia no antigo Israel, enquanto lembrança subsiste em lembranças que por vezes se opõem à realidade mesmo quando afixadas. Nesse caso, os contatos das recordações sociais e culturais com o passado confrontam com suas fontes. A escrita existe, mas a mnēmē coletiva elemento essencial identitário que não deve ser submetido a uma analogia com o texto - ainda transita entre a história e os mitos locais, ou “palavra por palavra”, respeitando o portador da mnēmē do lugar (ou mnemōn do lugar). Sem, no entanto, revelar a posse de procedimentos mnemotécnicos específicos.

\footnotetext{
${ }^{22}$ De forma conceptual, a grandeza social seria: “Uma unidade de ação política e social só se constitui por meio de conceitos pelos quais ela se delimita, excluindo outras, de modo a determinar a si mesma. Empiricamente, um grupo pode se constituir por meio do comando ou do consenso, do contrato ou da propaganda, da necessidade ou do parentesco, de alguma outra coisa ou de uma outra maneira qualquer. Mas não podem estar ausentes os conceitos pelos quais o grupo possa se reconhecer e se autodeterminar, caso deseje apresentar-se como uma unidade de ação" (KOSELLECK, 2011b, p. 192).

${ }^{23}$ Conferir, por exemplo, Le Goff (2012); Ricœur (2014); Assmann (2011); Lavabre (2011).
} 
Por outro lado, o documento monumental, o artefato, é encenação de fato e registro escritural, post eventum "palavra por palavra". Essa diversidade de evidências e aquisições materiais não se compreende coerentemente, de forma indutiva, por isso o método aqui sugerido em nada diz respeito à quantificação. Para reafirmar na escrita historiográfica o artefato hebraico no conjunto das fontes primárias, nomeadamente um texto, faz-se necessário buscar nele as relações entre pequenos os reinos levantinos. ${ }^{24}$ Porque “falas tiveram lugar': elas produzem acontecimento", 25 na medida em que, contra as abstrações, o artefato que reproduz o acontecimento é o que nos aproxima da História. ${ }^{26}$

A esse propósito, conceituamos a escrita historiográfica como escrita literária, um meio de transmitir o resultado de pesquisas linguísticas e técnicas. Em que consiste a diferença entre literatura e historiografia? ${ }^{27}$ Ora, historiografia é um gênero literário, mas a distinção não é dada por apenas pactuar com o leitor e reportar-se aos eventos e ao povo, como se isso diferenciasse as "obrigações", como presume Menachem Brinker com o assentimento de Yairah Amit (AMIT, 2006, p. 2). Esta constatação é insuficiente na medida em que precisamos compreender as inscrições nos contextos do antigo Oriente-Próximo.

Na verdade, todo método da pesquisa histórica está fundado na distinção, entre as fontes, ${ }^{28}$ conceptualmente. Com relação à escrita historiográfica, como ciência ela é um processo operatório em forma de relato com fronteiras (o objeto passado e a atividade presente) que, segundo Certeau (2011, p. 27), "quer restaurar um esquecimento e encontrar os homens através dos traços que eles deixaram", mas que vai além do trabalho científico. Na operação, a produção de sentido ocorre pela difícil tarefa de remontar ao acontecimento, que nunca é dado nem

\footnotetext{
${ }^{24}$ Tem-se adotado nas definições para os pequenos reinos levantinos, mesmo quando analisados individualmente, as postulações de Trevor Bryce (2012, p. 195-207) baseadas em comprovações do final do Bronze Tardio e início do Ferro I, como sendo entidades políticas independentes baseadas em linhagem de parentesco, governadas por uma dinastia local, também chamada de "governo de elite", cuja capital servia como centro administrativo de todo o reino, e à qual outros centros urbanos menores e periferias de campesinos e pastoralistas eram subjugados.

${ }^{25}$ Expressão formulada por Arlette Farge (2015, p. 77) no capítulo “Do acontecimento", em sua importante obra.

${ }^{26}$ Temos em mente a expressão, emblemática para o historiador, de Michel de Certeau (2011, p. 81), "o fato é a diferença".

${ }^{27}$ Esta é a questão formulada por Yairah Amit (2006, p. 2); cf. Certeau (2011, p. 27), para quem a historiografia é “um gênero literário próprio".

${ }^{28}$ Famoso postulado de Arnaldo Momigliano (1983a, p. 246); conferir Finley (2001a, p. 42). Para Finley (2001c, p. 105), “o método histórico não é ensinável, e em todo caso nós o fazemos muito".
} 
postulado, ${ }^{29}$ partindo ou não de fonte definida porque a escrita da história se aplica também aos silêncios, às lacunas.

Caracteristicamente, a história narrativa é uma das formas mais antigas de interação. Por isso Reinhart Koselleck (2016, p. 165) afirmou ser "possível considerar 'História' como um conceito fundamental permanente da sociedade, em especial da sociabilidade", ao mesmo tempo em que possibilita a existência explanatória da própria sociedade cujos membros ainda pertencem a estamentos, por força das hierarquias estabelecidas pelo Estado e da não identificável cidadania de todos os seus indivíduos (formalmente igualitária).

Dentre as suas distinções, há documentos privados e públicos. Dos documentos públicos, há os produzidos pelo Estado, de uma subdivisão do Estado ou num templo; destes, temos aqueles restritos à circulação privada e aqueles que são destinados ao conhecimento do público. Mas sabemos com Finley (2001b, p. 96) que "os próprios documentos não fazem perguntas, embora às vezes eles forneçam respostas”. ${ }^{\circ}$ A par do acontecimento, limitado no discurso das fontes, buscamos o fato histórico, o sentido. ${ }^{31}$

Uma das teorias para os estudos bíblicos de texto e contexto propõe abarcar o significado e a função originais do desenvolvimento literário, percebendo os aspectos do mundo além do texto (os contextos marginais apresentados globalmente no antigo Oriente-Próximo). ${ }^{2}$ Nesse projeto do novo historicismo propõe-se interconectar textos e história ou contexto, sem precisar uma relação causal. Ora, esta teoria amplia o conceito de contexto, mas é impraticável por causa do grande complexo textual de longuíssima duração que são os cenários da Bíblia hebraica, para além da significativa complexidade do espaço-tempo múltiplo. Mas há distinções.

\footnotetext{
${ }^{29}$ Aludimos a uma pedagogia de Marc Bloch, seguida por Carlo Ginzburg e Jacques Le Goff.

${ }^{30}$ Para Certeau (2011, p. 104), "o acontecimento é aquele que recorta, para que haja inteligibilidade; o fato histórico é aquele que preenche para que haja enunciados de sentido. O primeiro condiciona a organização do discurso; o segundo fornece os significantes, destinados a formar, de maneira narrativa, uma série de elementos significativos".

${ }^{31}$ Os hermeneutas designam por "reserva de sentido".

${ }^{32}$ Referimo-nos a uma pesquisa de Steven Weitzman (2016).
} 
Na Mesopotâmia, o sentido da história reflete a percepção acerca do próprio mundo, depreende-se daí que essa visão "se insere num universo descrito pelas cosmogonias da literatura mitológica segundo as quais o disco terrestre, rodeado de um oceano circular, separa em duas metades a esfera do universo". Assim Cécile Michel (2014, p. 242) compreende que a visão de mundo se confunde com a visão política e na descrição, não raro, "mistura topônimos atestados em épocas diferentes ou que designam duas realidades geograficamente diferentes no curso do tempo". O desenvolvimento da comunicação de um governante, por exemplo, depende da extensão do seu poder e, portanto, da inclusão de culturas. Numa aproximação às poleis, Israel insere-se no contexto das sociedades de comunicação oral e escrita, particularmente poética, mas acrescentaríamos a linguagem comunicativa iconográfica, seja como resultado do efeito das imagens mentais como ilusão criativa, seja como personificação de mnēmē cultural.

É importante salientar que "a escritura das leis e as novas práticas do processo jurídico priorizaram a testemunha, aquele que viu o fato, mais do que aquele que jurava dizer a verdade" (THEML, 2002, p. 12). Mas não apenas, posto que o historiógrafo não se ressente, por vezes, em reescrever lendas e mitos. A interferência no escriba não acontece diretamente pelo público, como no poeta grego, mas indiretamente pelo patrono e pelas tradições em vigência. A exposição do saber em forma de objeto, atendia, portanto, à necessidade do público de ouvir e ver. Segundo Neyde Theml (2002, p. 14), os gregos atenderam a isso com o teatro; podemos dizer que povos do antigo Oriente-Próximo encenaram os acontecimentos por meio da iconografia, em miniatura e monumentos. Além disso, conceptualmente a política e a natureza são a mesma coisa no antigo OrientePróximo, exatamente o contrário para o mundo da polis.

A priorização pelo ver ocorre a partir do século VI A.E.C., valorizando a partir daí o autoptes (aquele que viu com seus próprios olhos) e o superstes (aquele que ainda subsiste) e validando as inscrições, ainda que as mesmas sejam na 
maioria das vezes interpretativas. 33 No período greco-romano do século $\mathrm{V}$ ao I A.E.C. inventa-se "o 'discurso histórico', o conceito de testemunho, a lógica da história, e funda a história na verdade" (LE GOFF, 2012, p. 113). Afora o impacto da conceitualização de vêrì simŭlis ("verdadeiro"), evento intelectual ainda não experimentado até a Idade do Ferro, as linguagens artefactuais demonstram desde antes dos jônicos a permanência de grandezas socioétnicas de comunicação oral do ouvir e do ver que elaboram suas informações. Em forma de inscrição ou em forma de escultura, "a imagem anuncia, ela produz uma ausência e, ao mesmo tempo, torna presente a coisa ausente" (THEML, 2002, p. 18). De fato, observa-se uma grande mudança do ponto de vista do procedimento, pois antes do século VI A.E.C. "nunca ocorria o questionamento sobre a história enquanto tal. Sua evidência não era questionada" (HARTOG, 2013, p. 20).

Com relação a isso, nos contextos dos israelitas os monumentos projetam evidências, num horizonte de análise com documentos (camadas editoriais) hebraicos, pois o tempo relevante que surge "por ocasião de momentos de encontro ou de choque entre duas culturas e duas formas de história: como se pode verificar em relação ao mundo mesopotâmico e ao antigo Israel" (HARTOG, 2013, p. 21). Essas histórias ainda não são uma história do olhar e da visão, e convém não deixar de reconhecer que a historiografia régia e monumental é frequentemente legitimadora. Como quem reconhece ser uma grande empreitada a pesquisa de artefatos na historiografia hebraica, agrada-nos saber que "a historiografia dos livros dos Reis dá pouca margem à dúvida. A sua estrutura é clara e o texto como um todo parece ser obra de um historiador" (SETERS, 2008, p. 261).

Tal posição implica a vinculação dos testemunhos arqueológicos ao método da pesquisa. "A reconstrução de sequências de eventos e as personalidades por trás deles permanecem preservadas do historiador, enquanto questões de definição cultural e mudança, dentro de um contexto específico e em uma paisagem mais ampla, concernem ao arqueólogo" (GATES, 2007, p. 65). Ambos, na reconstrução

\footnotetext{
${ }^{33} \mathrm{O}$ que de certa forma é um ganho para o testemunho, considerando que os gregos costumavam adulterar textos antigos dando-Ihe autoria própria (SETERS, 2008).
} 
da mentalidade e os modos de ser de indivíduos e estamentos sociais, buscam as ambientações. Atualmente o pesquisador dispõe de dados sobre meio ambiente, materiais orgânicos de subsistência e instrumentos de defesa, três tópicos de relevância imediata para as políticas e economias antigas, impondo uma interdependência de disciplinas acadêmicas.

Mesmo com esta compreensão, Marie-Henriette Gates (2007, p. 76-77) lembra que na pesquisa do antigo Oriente-Próximo, paradoxalmente, a redefinição dos parâmetros e títulos institucionais de abordagens ("culturas", "civilizações", "artes", "literaturas") tem impedido o trabalho coletivo transdisciplinar. Para ela, não deve existir relutância em admitir que as limitações de um tipo de documentação podem ser compensadas por outros documentos e as perspectivas independentes podem ser conectadas. Eis o espírito metodológico da pesquisa histórica!

Ao fim e ao cabo, o equilíbrio consiste em reconhecer as várias formas de escrever a História e os acessos possíveis para remontar e apresentar os fatos históricos em uma forma narrativa. O artefato é político! Exclamaria Finley (2001c, p. 124) a propósito da pesquisa sobre os fatos históricos, "mas sem hipótese, não há explicação; só há reportagem e taxonomia bruta, erudição no sentido mais estrito".

\section{Objetificação na pesquisa: 0 acontecimento na linguagem}

A abordagem metodológica, encetada por algumas hipóteses, além de ser a forma de apresentar teoricamente a pesquisa ("religiosa", política etc.) tem, por um lado, o propósito de afirmar fortemente os contextos e a transdisciplinaridade, sejam quais forem os ambientes identificadores. A natureza da sociedade e seu tempo afixam-se nas linguagens das fontes correspondentes, por isso o destaque para o discurso político, algo poliglota e, como a maioria das fontes, apresentando em cada fragmento sublinguagens em correspondência com os acontecimentos. Mas as fontes não são necessariamente a história a cujo conhecimento queremos chegar. Referimo-nos aos contextos primários, oferecidos pelo modo de discurso 
institucionalizado que torna possível a enunciação, apresentados por várias histórias. ${ }^{34}$ No conjunto das diferenças estão a apropriação e a expropriação do político nas ambientações das linguagens religiosas. Como a investigação das fontes consistirá na tarefa de escavar os acontecimentos enunciados, a historiografia de fatos políticos expõe-se contextualmente como événementielle, ou seja, na linguagem deve haver um acontecimento.

Especialmente quanto ao que se refere à política, "a história nunca se identifica com seu registro linguístico nem com sua experiência formulada, condensada oralmente ou por escrito, mas também não é independente dessas articulações linguísticas" (KOSELLECK, 2011b, p. 196). Perceberemos que as linguagens das inscrições monumentais enquadram-se dentre aquelas geradas pelas atividades, práticas e contextos da sociedade, com certa ambivalência (POCOCK, 2003, p. 66, 74-75), haja vista os casos assírios e israelitas em que um mesmo acontecimento é registrado várias vezes com descrições, conjeturas, pontos de vista partidários e em suportes diferentes. Especificamente aqui, a vantagem do método comparativo na pesquisa da história é que as linguagens políticas são diversificadas e intencionais.

Cabe afirmar que a complexidade em afixar um documento que tornou-se autoritativo para uso em festejos cúlticos na Antiguidade, como objeto de pesquisa histórica, exige-nos enunciar, precipuamente, uma arqueologia literária desse mesmo documento e sua justificativa. Ao estabelecermos as regras teóricas, os domínios de abordagem nos serão fornecidos. A contextualização por si da fonte literária não seria suficiente para possibilitar um amplo conhecimento do acontecimento registrado.

No campo religioso, a cultura como arte e tradição sobrepõe às questões biológicas e de concepções mentais por ser resultado de interações, relaciona-se com a sociedade. Esta posição desvincula-nos do debate sobre os símbolos, pelo fato de "cultura", como conceito polissêmico, não ser um termo autoexplicativo

\footnotetext{
${ }^{34}$ Sobre isto, no ensaio fundamental de John G.A. Pocock (2003, p. 64). Na leitura do ensaio de Pocock sugerimos ter em mente, ao menos em alguns pontos, o ensaio de Jacques Revel (2009).
} 
(CARDOSO, 2005b). Por outras palavras, quer dizer que a nossa abordagem da ordem simbólica baseia-se na premissa de que "a ordem simbólica é a que confere significado e relaciona o sujeito com seu lugar na ordem social de outros sujeitos" (CARDOSO, 2005a, p. 80).

Isso tem validade metodológica para outro domínio da linguagem, a exegese textual 35 , considerando que a pictografia da narração é uma tentativa de plenificar as divindades, cuja natureza reflete os sujeitos a elas relacionados. Mesmo com a atestação material ou historicidade, temos motivos para cautela. Considerando que os lugares e os objetos são silenciosos e raríssimas camadas literárias são obra de autoptes e de superstes, comprova-se assim que a sociedade pode ser vista como sujeito e reificada como objeto do conhecimento quando nos referimos aos artefatos. Cabe ainda uma justificação acerca do uso de "anais" como registro histórico oficial no antigo Oriente-Próximo. Nesse sentido, arquivo, seja lá o que contenha - listas, anais, historiografia, crônicas, profecias, novela, biografia, código de leis -, deve receber classificação.

Na verdade, pouco diferenciamos entre a significância e conceituação dos "anais", a não ser em gênero literário não historiográfico, assim como Arnaldo Momigliano (1983b) não diferenciava a escrita historiográfica bíblica da escrita de toda outra história, e criticava a redução, justificada pela qualidade intelectual, de variadas historiografias a ficção. O problema seria, então, reduzir o artefato literário à expressão do ponto de vista partidário-ideológico ou a uma atitude retórica, levando em máxima consideração a forma de exposição dos fatos, não o método da pesquisa e a aptidão em estabelecer os fatos. No caso particular, o artefato ou a camada literária hebraica delimita o período a ser pesquisado.

\footnotetext{
${ }^{35}$ Enunciando como se fora algo notório, Carlo Ginzburg (2011, p. 157) informa: "Como se sabe, a crítica textual nasceu depois da primeira [a invenção da escrita] (quando se decidiu transcrever os poemas homéricos) e consolidou-se depois da segunda [a invenção da imprensa] (quando as primeiras e frequentemente apressadas edições dos clássicos foram substituídas por edições mais confiáveis). Inicialmente, foram considerados não pertinentes ao texto os elementos ligados à oralidade e à gestualidade; depois, também os elementos ligados ao caráter físico da escrita".
} 


\section{Conclusão}

Embora a Bíblia hebraica seja uma obra fundante, as suas historiografias, prosas de ficção e memórias não são inteiramente nem história nem narrações puramente míticas. Por isso, suas brilhantes sínteses teológicas não devem ser reduzidas a uma obra de legitimação, mesmo considerando, segundo enunciado de Philippe Abadie (2009, p. 33), "lintentionnalité historienne des auteurs sacrés", nem mero produto cultural de um longo período da história. Processualmente: observar as narrações e explicar historicamente a continuité textuelle como produto de uma representação identitária coletiva.

Assim sendo, tomamos por relevante a nossa impossibilidade de constatar in loco os fatos. Com efeito, aqui encontramo-nos com a consistente importância da Bíblia hebraica como documento, em suas camadas literárias de natureza historiográfica. O elo significativo de tantas narrações hebraicas prende-se diretamente ou ao israelita, determinante para a cristalização das identidades, ou ao lugar cúltico, para o caso de registro de fundação do lugar onde o antepassado ancestral teve uma experiência com a divindade (GIBERT, 1986, p. 299). Em adição, como compreendeu Le Goff (2012, p. 425), "o povo hebreu é o povo da memória por excelência”.

\section{REFERÊNCIAS}

ABADIE, Philippe. L'histoire d'Israël entre mémoire et relecture. Paris: Éditions du Cerf, 2009.

ALTER, Robert. A arte da narrativa bíblica. Tradução de Vera Pereira. São Paulo: Companhia das Letras, 2007.

AMIT, Yairah. Looking at history through literary glasses too. In: AMIT, Yairah et al (ed.). Essays on ancient Israel in its Near Eastern context. A tribute to Nadav Na'aman. Winona Lake: Eisenbrauns; Pennsylvania State University Press. 2006. p. 1-15. 
ASSMANN, Aleida. Espaços da recordação: formas e transformações da memória cultural. Tradução de Paulo Soethe (coord.). Campinas: Editora da Unicamp, 2011.

BLOCH, Marc. Apologia da história, ou O ofício de historiador. Tradução de André Telles. Rio de Janeiro: Zahar, 2009.

BRYCE, Trevor. The world of the neo-hitite kingdoms: a political and military history. Oxford: Oxford University Press, 2012.

CARDOSO, Ciro Flamarion S. Etnia, nação e a Antiguidade: um debate. In: NOBRE, Chimene Kuhn; CERQUEIRA, Fabio Vergara; POZZER, Katia Maria Paim (ed.).

Fronteiras e etnicidade no mundo antigo. Pelotas: Editora Ufpel; Canoas: Editora da Universidade Luterana do Brasil, 2005b. p. 87-104.

CARDOSO, Ciro Flamarion S. Um historiador fala de teoria e metodologia: ensaios. Bauru: Editora da Universidade do Sagrado Coração, 2005a.

CERTEAU, Michel de. A escrita da história. 3. ed. Tradução de Maria de Lourdes Menezes. Rio de Janeiro: Forense Universitária, 2011.

CHÂTELET, François. La naissance de l'histoire. Paris: Éditions de Minuit, 1996. v. 1.

CUNHA, Manuela Carneiro da. "Cultura" e cultura: conhecimentos. In: CUNHA, Manuela Carneiro da. Cultura com aspas e outros ensaios. São Paulo: Ubu, 2017. p. 304-369.

DAY, Mark; RADICK, Gregory. Historiographic evidence and confirmation. In: TUCKER, Aviezer (ed.). A companion to the philosophy of history and historiography. Oxford: Wiley-Blackwell, 2011. p. 87-97.

DURKHEIM, Émile. As formas elementares da vida religiosa. Tradução de Paulo Neves. São Paulo: Martins Fontes, 2014.

ESPIÑA, Yolanda. Ruptura dos binômios: civilização, cultura, identidade. In: FERNANDES, Maria Fernanda Lombardi; ROVAI, Mauro Luiz; LANDINI, Tatiana Savoia (org.). Civilização: sentidos e paradoxos. São Paulo: Editora FAP-UNIFESP, 2014. p. 149161.

FARGE, Arlette. Lugares para a história. Tradução de Fernando Scheibe. Belo Horizonte: Autêntica, 2015.

FINLEY, Moses I. Comment les choses authentiquement furent. In: FINLEY, Moses I. Sur l'histoire ancienne: la matière, la forme et la méthode. Traduction de Jeannie Carlier. Paris: Éditions La Découverte \& Syros, 2001c, p. 97-124.

FINLEY, Moses I. L'histoire ancient et ses sources. In: Sur l'histoire ancienne: la matière, la forme et la méthode. Traduction de Jeannie Carlier. Paris: Éditions La Découverte \& Syros, 2001a. p. 41-67. 
FINLEY, Moses I. Le document. In: FINLEY, Moses I. Sur l'histoire ancienne: la matière, la forme et la méthode. Traduction de Jeannie Carlier. Paris: Éditions La Découverte \& Syros, 2001b, p. 68-96.

GATES, Marie-Henriette. Archaeology and the ancient Near East: methods and limits. In: SNELL, Daniel C. (ed.). A companion to the Ancient Near East. Malden, MA: Blackwell Publishing, 2007. p. 65-78.

GIBERT, Pierre. A Bíblia na origem da história. Tradução de M. Cecília de M. Duprat. São Paulo: Paulinas, 1986.

GINZBURG, Carlo. O fio e os rastros: verdadeiro, falso, fictício. Tradução de Rosa Freire d’Aguiar e Eduardo Brandão. São Paulo: Companhia das Letras, 2007.

GINZBURG, Carlo. Sinais: raízes de um paradigma indiciário. In: GINZBURG, Carlo. Mitos, emblemas, sinais: morfologia e história. 2. ed. Tradução de Federico Carotti. São Paulo: Companhia das Letras, 2011. p. 143-179.

HARTOG, François. Evidência da história: o que os historiadores veem. Tradução de Guilherme João de Freitas Teixeira. Belo Horizonte: Autêntica, 2013.

HOLM, Tawny L. Ancient Near Eastern literature: genres and forms. In: SNELL, Daniel C. (ed.). A companion to the ancient Near East. Malden, MA: Blackwell Publishing, 2007. p. 269-288.

JEFFARES, Ben. Philosophy of archaeology. In: TUCKER, Aviezer (ed.). A companion to the philosophy of history and historiography. Oxford: Wiley-Blackwell, 2011. p. 330-341.

KOSELLECK, Reinhart. A configuração do moderno conceito de história. In: KOSELLECK, Reinhart et al. O conceito de história. Tradução de René E. Gertz. Belo Horizonte: Autêntica, 2016. p. 119-184.

KOSELLECK, Reinhart. A semântica histórico-política dos conceitos antitéticos assimétricos. In: KOSELLECK, Reinhart. Futuro passado: contribuição à semântica dos tempos históricos. Tradução de Wilma Patrícia Maas e Carlos Almeida Pereira. Rio de Janeiro: Contraponto: Editora da PUC-RJ, 2011b. p. 191-231.

KOSELLECK, Reinhart. Ponto de vista, perspectiva e temporalidade: contribuição à apreensão historiográfica da história. In: KOSELLECK, Reinhart. Futuro passado: contribuição à semântica dos tempos históricos. Tradução de Wilma Patrícia Maas e Carlos Almeida Pereira. Rio de Janeiro: Contraponto: Editora da PUC-RJ, 2011a. p. 161-188.

LAVABRE, Marie-Claire. Historiography and memory. In: TUCKER, Aviezer (ed.). A companion to the philosophy of history and historiography. Malden, MA: Blackwell Publishing, 2011. p. 362-370.

LE GOFF, Jacques. História e memória. 6. ed. Tradução de Bernardo Leitão et al. Campinas: Editora da Unicamp, 2012. 
LEMOS, Tracy Maria. Kinship, community, and society. In: NIDITCH, Susan (ed.). The Wiley Blackwell companion to ancient Israel. Malden, MA: Blackwell Publishing, 2016. p. 379-395.

LENCIONI, Sandra. Região e geografia. São Paulo: Editora da USP, 2009.

LÉVI-STRAUSS, Claude. O pensamento selvagem. 12. ed. Tradução de Tânia Pellegrini. Campinas: Papirus, 2013.

MACDONALD, Graham; MACDONALD, Cynthia. Explanation in historiography. In: TUCKER, Aviezer (ed.). A companion to the philosophy of history and historiography. Malden, MA: Blackwell Publishing, 2011. p. 131-141.

MATTHEWS, Victor H. The history of bronze and iron Age Israel. Oxford: Oxford University Press, 2019.

MENESES, Ulpiano T. Bezerra de. A história, cativa da memória? Para um mapeamento da memória no campo das Ciências Sociais. Revista do Instituto de Estudos Brasileiros, São Paulo, n. 34, p. 9-24, 1992.

MICHEL, Cécile. Vision du monde. In: BORDREUIL, Pierre; BRIQUEL-CHATONNET, Françoise; MICHEL, Cécile (dir.). Les débuts de l'histoire: civilisations et cultures du Proche-Orient ancien. Nouvelle édition revue et augmentée. Paris: Éditions Khéops, 2014. p. 242-245.

MOMIGLIANO, Arnaldo. Études bibliques et études classiques: simples réflexions sur la méthode historique. In: MOMIGLIANO, Arnaldo. Problèmes d'historiographie ancienne et moderne. Traduction de Alain Tachet. Paris: Éditions Gallimard, 1983b. p. $475-482$.

MOMIGLIANO, Arnaldo. L'histoire ancienne et l'antiquaire. In: MOMIGLIANO, Arnaldo. Problèmes d'historiographie ancienne et moderne. Traduction de Alain Tachet. Paris: Éditions Gallimard, 1983a. p. 244-293.

POCOCK, John G. A. O conceito de linguagem e o métier d'historien. In: POCOCK, John G. A. Linguagens do ideário político. Tradução de Fábio Fernandez. São Paulo: Editora da USP, 2003. p. 63-82.

REDE, Marcelo. História e cultura material. In: CARDOSO, Ciro Flamarion; VAINFAS, Ronaldo (org.). Novos domínios da história. Rio de Janeiro: Elsevier, 2012. p. 133-150.

REVEL, Jacques. Retornar ao acontecimento - um itinerário historiográfico. In: REVEL, Jacques. Proposições: ensaios de história e historiografia. Tradução de Claudia O'Connor dos Reis. Rio de Janeiro: Editora da UERJ, 2009. p. 73-95.

RICCEUR, Paul. A memória, a história, o esquecimento. Trad. de Alain François et al. Campinas: Editora da Unicamp, 2014. 
RÜSEN, Jörn. História viva. Tradução de Estevão de Rezende Martins. Brasília: Editora da UnB, 2010. (Teoria da história III: formas e funções do conhecimento histórico).

RÜSEN, Jörn. Razão histórica. Tradução de Estevão de Rezende Martins. Brasília: Editora da UnB, 2001. (Teoria da história I: os fundamentos da ciência histórica).

RÜSEN, Jörn. Reconstrução do passado. Tradução de Asta-Rose Alcaide. Brasília, DF: Editora da UnB, 2007. (Teoria da história II: os princípios da pesquisa histórica).

SANTOS, João Batista Ribeiro. Estrutura literária e cultura iconográfica nas entrelinhas da Bíblia hebraica. In: SANTOS, João Batista Ribeiro. Primeiro testamento: estudos teóricos e exegéticos. São Bernardo do Campo: Editora da Faculdade de Teologia da UMESP, 2018b. p. 31-46.

SANTOS, João Batista Ribeiro. Sobre cultura material e a Bíblia: limite epistemológico. In: SANTOS, João Batista Ribeiro. Primeiro testamento: estudos teóricos e exegéticos. São Bernardo do Campo: Editora da Faculdade de Teologia da UMESP, 2018a. p. 19-29.

SANTOS, João Batista Ribeiro. Tempo e memória do passado: apreensão de culturas por meio de experiências. In: SANTOS, João Batista Ribeiro. Primeiro testamento: estudos teóricos e exegéticos. São Bernardo do Campo: Editora da Faculdade de Teologia da UMESP, 2018c. p. 47-72.

SETERS, John Van. Em busca da história: historiografia no mundo antigo e as origens da história bíblica. São Paulo: Editora da USP, 2008.

THEML, Neyde. Linguagem e comunicação: ver e ouvir na antiguidade. In: THEML, Neyde (org.). Linguagens e formas de poder na antiguidade. Rio de Janeiro: Mauad: FAPERJ, 2002. p. 11-24.

UEHLINGER, Christoph. Distinctive or diverse? Conceptualizing ancient israelite religion in its Southern levantine setting. In: KNOPPERS, Gary N. et al. (ed.). Hebrew Bible and ancient Israel. Tübingen: Mohr Siebeck, 2015. v. 4. p. 1-24.

VILLARD, Pierre. Des textes au service du pouvoir. In: BORDREUIL, Pierre; BRIQUELCHATONNET, Françoise; MICHEL, Cécile (dir.). Les débuts de l'histoire: civilisations et cultures du Proche-Orient ancien. Nouvelle édition revue et augmentée. Paris: Éditions Khéops, 2014. p. 358-365.

VIVEIROS DE CASTRO, Eduardo. Metafísicas canibais: Elementos para uma antropologia pós-estrutural. São Paulo: Cosac Naify: N-1 Edições, 2015.

VIVEIROS DE CASTRO, Eduardo. O conceito de sociedade em antropologia. In: VIVEIROS DE CASTRO, Eduardo. A inconstância da alma selvagem e outros ensaios de antropologia. 5. ed. São Paulo: Cosac Naify, 2013. p. 295-316.

WEITZMAN, Steven. Text and context in biblical studies: a brief history of a troubled relationship. In: NIDITCH, Susan (ed.). The Wiley Blackwell companion to ancient Israel. Malden, MA: Blackwell Publishing, 2016. p. 67-84. 